\title{
Trajectories of sinking particles and the catchment areas above sediment traps in the northeast Atlantic
}

\author{
by Joanna Waniek ${ }^{1,2}$, Wolfgang Koeve ${ }^{1,3}$ and Ralf D. Prien ${ }^{4,5}$
}

\begin{abstract}
A Lagrangian analysis of particles sinking through a velocity field observed by Eulerian frame measurements was used to evaluate the effects of horizontal advection and particle sinking speed on particle fluxes as measured by moored sediment traps. Characteristics of the statistical funnel above moored deep-ocean sediment traps at the German JGOFS quasi-time series station at $47 \mathrm{~N}, 20 \mathrm{~W}$ (Biotrans site) were determined. The analysis suggests that the distance and direction between a given sediment trap and the region at the surface where the particles were produced depends on the mean sinking velocity of the particles, the horizontal velocity field above the trap and the deployment depth of the trap. Traps moored at different depths at a given mooring site can collect particles originating from different, separated regions at the surface ocean. Catchment areas for a given trap vary between different years. Typical distances between catchment areas of traps from different water depth but for a given time period (e.g., the spring season) are similar or even larger compared to typical length scales of mesoscale variability of phytoplankton biomass observed in the temperate northeast Atlantic. This implies that particles sampled at a certain time at different depth horizons may originate from completely independent epipelagic systems. Furthermore catchment areas move with time according to changes in the horizontal flow field which jeopardizes the common treatment of interpreting a series of particle flux measurements as a simple time series. The results presented in this work demonstrate that the knowledge of the temporal and spatial variability of the velocity field above deep-ocean sediment traps is of great importance to the interpretation of particle flux measurements. Therefore, the one-dimensional interpretation of particle flux observations should be taken with care.
\end{abstract}

\section{Introduction}

The determination of the vertical flux of particulate material from the euphotic zone to the deep sea is relevant to many biogeochemical issues including global element budgets,

1. Institut für Meereskunde, Düsternbrooker Weg 20, 24105 Kiel, Germany.

2. Present address: School of Ocean and Earth Science, Southampton Oceanography Centre, Empress Dock/European Way, Southampton, SO14 3ZH, United Kingdom.email: jowa@soc.soton.ac.uk

3. Institut für Ostseeforschung, Warnemünde, Seestraße 15, 18119 Rostock, Germany.

4. Institut für Experimentelle und Angewandte Physik, Christian Albrechts Universität, Leibnizstr. 11, 24098 Kiel, Germany.

5. Ocean Engineering Division, Southampton Oceanography Centre, Empress Dock, Southampton SO14 3ZH, United Kingdom. 
estimates of new production of phytoplankton or studies of the transformations of matter within intermediate water depths (Honjo, 1996). Through the vertical transport of particles events that take place at the sea-surface are transmitted to the deep ocean. Therefore, seasonal variation of productivity in the euphotic zone, like the occurrence of spring phytoplankton blooms, can have significant effects on the flux of particles to the deep sea and its underlying sediments (Deuser and Ross, 1980; Billet et al., 1983; Asper et al., 1992; Pfannkuche, 1993). Fluxes of sinking particles are commonly measured using moored or tethered particle interceptor traps (Zeitzschel et al., 1978; Asper, 1996). Such traps have proven to be one of the few tools to investigate the transport of matter and metabolic energy to the deep sea directly (Knauer and Asper, 1989).

Passively settling particles are thought to be responsible for much of the transport of mass and energy from the euphotic zone to the deep ocean. Photosynthetic production by phytoplankton is a major source of these particles, which may consist either of single phytoplankton cells sinking directly through the water column (Billett et al., 1983) or after transformation into larger and rapidly sinking forms such as aggregates (Alldredge and Gotschalk, 1988; Asper, 1987) or zooplankton faeces (Urrere and Knauer, 1981). During the sinking through the water column these particles are prone to a variety of processes (e.g. remineralization, disaggregation, repackaging by zooplankton) which will affect the composition and amount of sinking matter. In addition advection of water displaces particles on the horizontal plane. Given that typical horizontal velocities of water are in the range of 10 to $20 \mathrm{~cm} \mathrm{~s}^{-1}$ and typical sinking speeds of large particles are 100 to $200 \mathrm{~m} \mathrm{~d}^{-1}$ (see references in Table 1), particles are moving with an angle of about $1^{\circ}$ relative to the surface of the ocean and may be displaced significantly from the place of their origin. It is, therefore, hardly predictable to what extent the flux of biogenic particles at a given depth and location in the deep sea is directly coupled to processes of particle production near the surface of the ocean at the respective site (Siegel et al., 1990). Although some studies have provided evidence for a direct, quasi one-dimensional, and fast coupling (Alldredge and Gotschalk, 1988; Deuser and Ross, 1980), one should be aware that it is purely due to the lack of adequate data of the environmental flow field that sediment trap data are typically interpreted as a one-dimensional time series of particle flux. Deuser et al. (1990) and Siegel and Deuser (1997) have shown the importance of the consideration of the horizontal advection acting on sinking particles to determine the catchment area of particle traps. The combination of particle modification and decay, advection and variable sinking speeds has the potential to significantly modify the spatial pattern of transmission of a surface signal to the deep oceans. Advective processes may even overwhelm the local surface production signals like in the case of lateral transport from areas of high production near the coast to the open ocean (Neuer et al., 1997). In this case seasonal and annual variations in deep-sea biogeochemistry and biology may even be controlled by lateral processes associated with ocean circulation rather than by local processes at the surface. 
Table 1. Sinking speeds $\left(\mathrm{m} \mathrm{d}^{-1}\right)$ for different kinds of particles.

Particle type

Phytoplankton

Ultraplankton

Net plankton

Diatoms

Algal aggregates

Marine snow

Protozoans

Foraminifera

Radiolarians

Acantharia

Zooplankton

Amphipoda

Chaetognata

Heteropoda

Pteropoda

Fecal material

Nauplii \& copepiodids

Crustacae

Salps

Aggregate
Sinking speed

$\mathrm{m} \mathrm{d}^{-1}$

$$
\begin{gathered}
<0.1-2 \\
<10-20 \\
10->70 \\
40-150 \\
1-368
\end{gathered}
$$

$30-4800$

350

600

875

435

1400

$760-2270$

$$
5-28
$$

$20-150$

$450-2700$

100
References

\author{
Bienfang (1980) \\ Smayda (1970) \\ Passow (1990) \\ Smetacek (1985) \\ Alldredge and Silver (1988)
}

Kuenen (1950)

Kuenen (1950)

Antia et al. (1993)

Smayda (1970)

Smayda (1970)

Vinogradov (1961)

Smayda (1970)

Paffenhoffer and Knowles (1979)

Small et al. (1979)

Bruland and Silver (1981)

Fowler and Knauer (1986)

Spatial inhomogeneities like frontal systems (Peinert and Miguel, 1994), mesoscale variability (Savidge et al., 1992), and coastal upwelling (Neuer et al., 1997; Antia et al., 1999) are affecting biomass and production of phytoplankton at the surface of the ocean on a global scale and to an extent that is now obvious from remote sensing of ocean color. The influence of mesoscale dynamics on biological production (new, regenerated, total) and export to the deep ocean based on modeling studies is summarized by Garçon et al. (2001). For the Biotrans area the calculated impact of eddies on new production is in the order of $50 \%$, and on total primary production of $25 \%$ (by Garçon et al. (2001) indicated in Table 1 as NABE area at 47N, 20W). Oschlies and Garçon (1998) show that new production could increase by $31 \%$, total primary production by $25 \%$ and POC export by $24 \%$ due to net impact of modeled eddies. The recorded particle flux at a given site and depth results from a combination of these temporally and spatially varying processes. A meaningful interpretation of flux data recorded by moored sediment traps relies on resolving the relative importance of any of these processes for a given study (Wefer and Fischer, 1993). Neuer $e t$ al. (1997) find high seasonality in particle flux at ESTOC (100 km north of Gran Canaria) closely linked to the end of the winter pigment maximum observed in historical CZCS images. In this paper we address some of the implications of a spatially and temporally variable flow field on the interpretation of flux measurements made by sediment traps at a 
fixed site. We use current meter data from a four-year-long record (summer 1993-summer 1997) sampled at the German JGOFS (Joint Global Ocean Flux Study) quasi time-series station at the Biotrans site $(47 \mathrm{~N}, 20 \mathrm{~W})$, a mooring position in the northeast Atlantic, to estimate the shapes of the path along which individual particles sink and the probable source locations at the sea surface from which sinking particles have originated for different collection periods for the assumptions selected.

\section{Theoretical considerations}

The spatial domain enclosing the likely origins for collected sinking particles has been termed the statistical funnel (Deuser et al., 1988; 1990). The intersection of the funnel with the sea surface can be thought of as circumscribing the catchment area of the trap (Siegel and Deuser, 1997). The geometrical form of both statistical funnel and catchment area are not known a priori and depend on the spatial and temporal pattern of the velocity field above the trap (e.g., dominating current directions), the length of the collection intervals and the sinking speed of the particles. The first step to identify the extent and displacement of the center of the statistical funnel relative to the trap location was made by Deuser $\mathrm{et} \mathrm{al}$. (1990) for the long term study site of the Ocean Flux Project (OFP) in the Sargasso Sea. The comparison of seven years of Coastal Zone Color Scanner (CZCS) pigment concentrations with carbon flux determinations at a water depth of $3200 \mathrm{~m}$ resulted in an idea about the location and the extent of the catchment area of the traps. The comparison suggested that the material collected by the trap moored in $3200 \mathrm{~m}$ water depth originated up to a few hundreds of kilometers northeast of the mooring site (Deuser et al., 1990). In a second more theoretical attempt, Siegel et al. (1990) investigated the variation of the catchment areas of traps as a function of mean sinking rate, the kinetic energy of a random mesoscale eddy field and the decorrelation time scale for Lagrangian particle motion. They presented examples of how the catchment area of traps varied as a function of the kinetic energy of a mesoscale eddy field and also showed how particle fluxes measured by traps at different depths on the same mooring line may either increase or decrease with depth, depending on the position of a bloom region relative to the mooring. Siegel and Deuser (1997) performed a Lagrangian analysis of particles sinking through a time-mean horizontal current overlaid with a quasi-random mesoscale eddy field to evaluate the effects of horizontal eddy diffusion and particle sinking rates on fluxes sampled by an idealized sediment trap. For their analysis they used observed vertical profiles of the time-mean and fluctuating horizontal currents and obtained the dispersion of the particles by the Markov chain method. They presented probability distributions of the points of origin at the sea surface of particles intercepted by traps for different sinking speeds and trap depths.

Here we develop a simulation model of particle trajectories above a moored sediment trap array in a realistic field of horizontal currents measured in an Eulerian frame at the 
traps' position. We are using a simpler approach, not considering the dispersion of particles but calculating the trajectory of a particle and the probable point of origin at the sea surface for every day of the time series. Using daily mean values of the observed current profiles, fluctuations on time scales less than one day are neglected. Therefore, the higher frequency components like inertial-internal wave motions are not considered. It can be assumed, however, that these components do not contribute significantly to the structure of the funnel (Siegel and Deuser, 1997). Lacking data of the mesoscale variability of the flow field around the moorings, we assumed that the observed velocity field (direction and magnitude of the velocity components) of any layer at the Biotrans site is representative for the area around the mooring. A hint that this assumption is justified for this area is given by the observations of the Topogulf project (Colin de Verdière et al., 1989) showing similar characteristics of the velocity field (300 m to $3900 \mathrm{~m}$ depth) for their section $\mathrm{D}$, which was located $1^{\circ}$ north of our mooring position. A detailed discussion of the horizontal current field observations carried out between 1992 and 1997 at the Biotrans position is presented elsewhere (Waniek and Zeitzschel, 2001).

Vertical fluid velocity may also affect the trajectories of sinking particles. On time and space scales of less than 100 days and $1000 \mathrm{~km}$, respectively, the time average of the vertical fluid velocity, however, is usually assumed to be much smaller than the average sinking speed of the particles (Gill, 1982) and, therefore, its influence on sinking particles can be neglected for the open ocean. For regions of active upwelling, usually found along the eastern boundaries of ocean basins, the vertical velocities may be significantly greater. Measurements indicate values of the order of $10^{-4} \mathrm{~cm} \mathrm{~s}^{-1}\left(10 \mathrm{~m} \mathrm{~d}^{-1}\right)$ off the west coast of North America (Roden, 1972). In the Gulf Stream vertical velocities of the order of $10^{-1} \mathrm{~cm} \mathrm{~s}^{-1}\left(100 \mathrm{~m} \mathrm{~d}^{-1}\right)$ are observed (Bower and Rossby, 1989). Vertical velocities associated with eddies and fronts of same order (of $10^{-1} \mathrm{~cm} \mathrm{~s}^{-1}$ or $100 \mathrm{~m} \mathrm{~d}^{-1}$ ) have been observed at the Iceland-Færœs Front (Pollard and Regier, 1992; Allen and Smeed, 1996). Nevertheless, the vertical velocities for the open ocean are much less than typical sinking speeds of large particles and even more than typical horizontal velocities. This justifies the assumption that the vertical fluid velocity can be neglected. It should be noted, however, that several processes (e.g., surface waves, tides, wind mixing and convective processes) lead to considerable vertical velocities in the upper layer that may alter the trajectories of sinking particles. With these simplifying assumptions the results should be considered as first step estimates of particle origins and trajectories only.

\section{Data and method description}

For our purposes, the observed velocity data at different water depths at the German JGOFS mooring at the Biotrans site at $47 \mathrm{~N}, 20 \mathrm{~W}$ were used. The measurements were obtained by moored Aanderaa current meters and an Acoustic Doppler Current Profiler 
(ADCP). The Aanderaa current meters were deployed in $100 \mathrm{~m}, 300 \mathrm{~m}, 550 \mathrm{~m}, 1000 \mathrm{~m}$, $2050 \mathrm{~m}$ and $3500 \mathrm{~m}$ water depth and recorded velocity magnitude and direction at $2 \mathrm{~h}$ intervals. The ADCP was deployed in $300 \mathrm{~m}$ water depth, had the same recording interval (time resolution) as the Aanderaa current meters and was looking toward the sea surface. Data from the ADCP current measurements were binned to $8 \mathrm{~m}$ vertical resolution. For our simulations we used a dataset based on four years of observations (summer 1993 to summer 1997) of daily averaged horizontal velocity measurements.

The sinking velocity of the particles was assumed to be constant with depth and a value of $100 \mathrm{~m} \mathrm{~d}^{-1}$ as suggested by Fowler and Knauer (1986) for fast sinking particles (e.g., aggregates) is used for standard runs. To explore the range of variability of catchment areas additional calculations were performed using sinking rates of $50 \mathrm{~m} \mathrm{~d}^{-1}$ and $200 \mathrm{~m} \mathrm{~d}^{-1}$. This is considered to be a realistic range for the bulk of the material collected by sediment traps (Smayda, 1970; Deuser et al., 1981; Fowler and Knauer, 1986; see also references in Table 1). Certain classes of particles like large foraminifera or shells of pteropods, however, may sink with significantly higher rates (Vinogradov, 1961; Berger and Piper, 1972; Takahashi and Bê, 1984) and are, therefore, less exposed to lateral displacement. Factors which influence the density of sinking particles (aggregation, disaggregation, remineralization and any other kinds of density changes due to particle modification) are neither taken into account nor discussed here.

Knowing the vertical profiles of the mean horizontal velocity field, its effects upon the trajectory of a sinking particle through the water column (from sea-surface to the depth of the trap) can be determined. For the calculations the process of sinking through the water column and its flow field is reversed, that is the particles are treated as if they are rising from the moored trap toward the surface with a constant, negative sinking speed and being displaced horizontally by the reversed horizontal flow field. This horizontal displacement for each day is calculated by multiplication of the reversed flow in the current depth layer by the time of one day. The trajectory of a particle then results from the progressive addition of the day to day displacements in the depth layers and the constant rise of the particle up to the surface.

The steps to obtain the catchment areas for a given trap deployment from our model are shown in Figure 1. The daily averaged $u$ and $v$ components of the velocity were calculated from the low-pass filtered data registered by the current meters and the ADCP at different depths (Fig. 1a). This dataset was re-arranged to get a series of vertical profiles, yielding one vertical profile of the horizontal velocity field ( $u$ and $v$ component) for each day (Fig. 1b). Next, discrete depth layers were defined between the current meter deployment depths and the vertical profiles were averaged over these layers. This resulted in daily means of horizontal velocity for every layer (Fig. 1c). With these data the day to day displacement of a particle rising from the trap with a sinking rate $S$ can be obtained by multiplying each velocity component by the time of one day (Fig. 1d). The position of the 
(a)

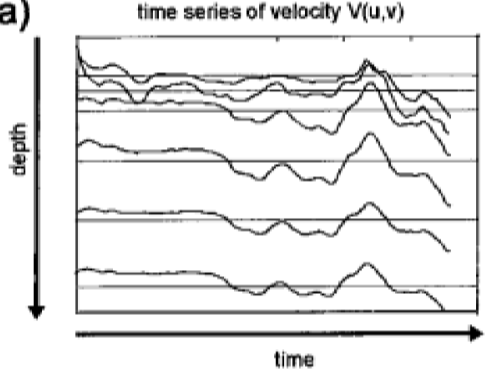

(c) define depth levels

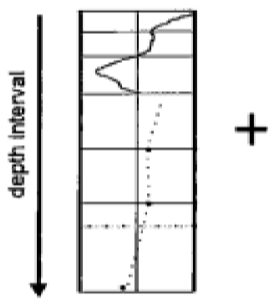

mean $V(u, v)$

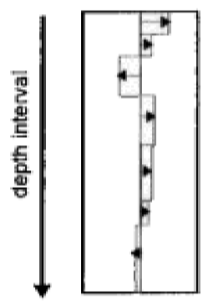

(b)

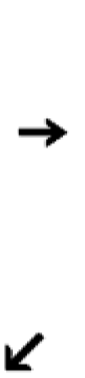

vertical profile of velocity $\mathrm{V}(\mathrm{z})$

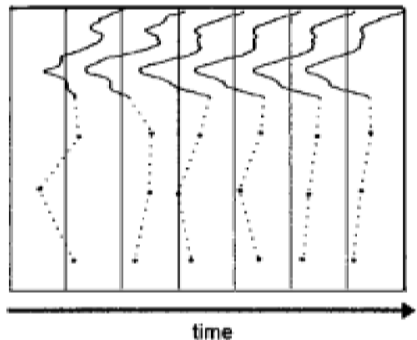

(d) sea surface
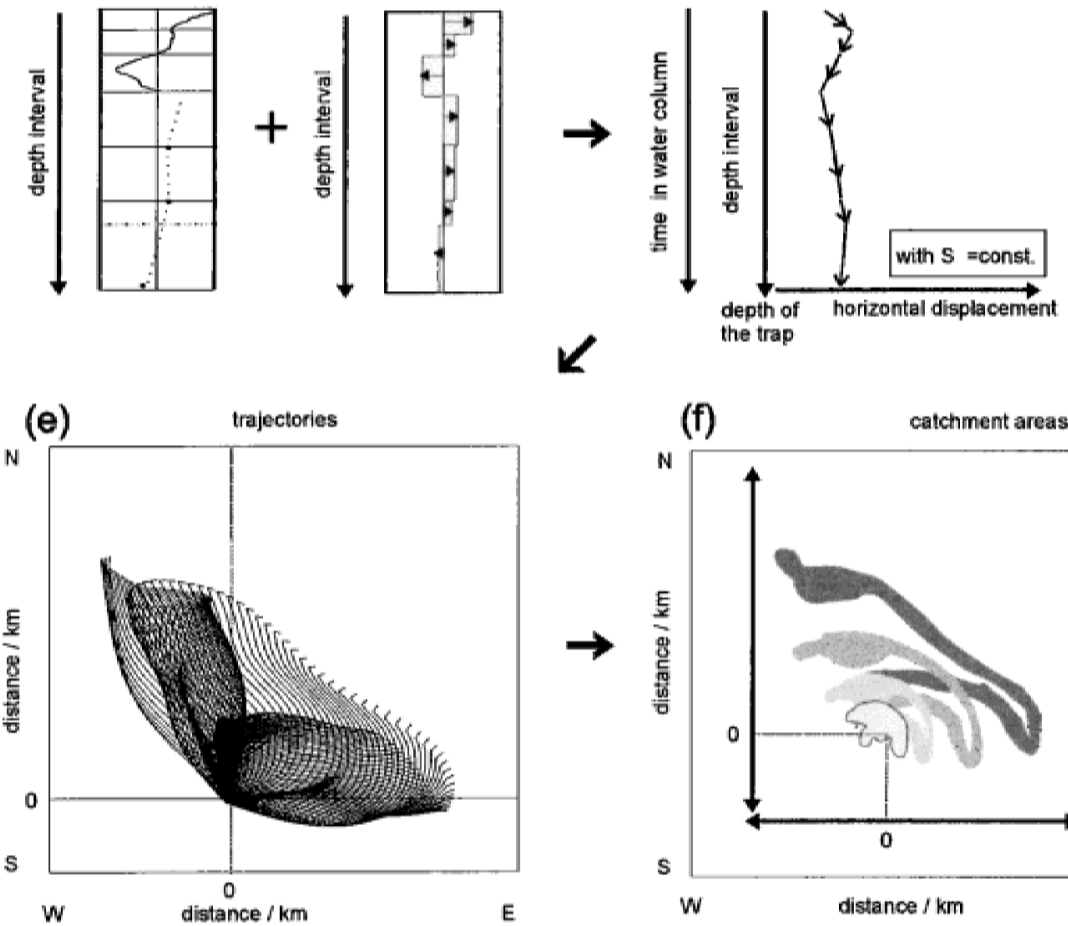

(f) catchment areas

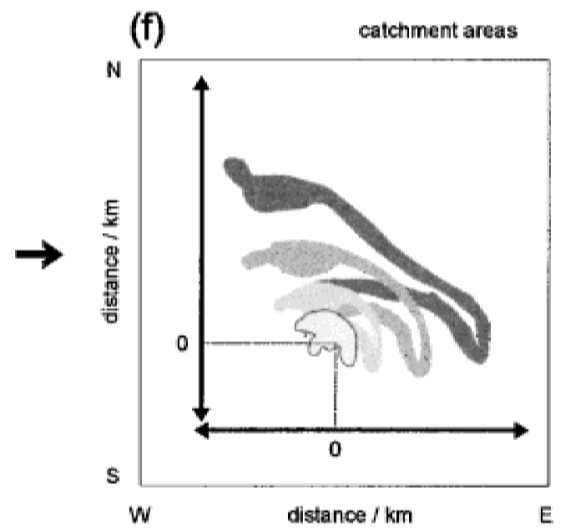

Figure 1. Schematic illustration of the method used in this work for the simulation of the statistical funnel and catchment areas of moored sediment traps. Time series from current meters or ADCP measurements are used as primary data source (a). Mean vertical profiles of the horizontal velocity components for each day of the time series are calculated (b). Discrete water layers are defined and ascribed with constant velocity values obtained by averaging the observed velocities from the two nearest current meter registrations (c). Horizontal displacement of a particle is estimated based on an assumption of the sinking speed $S$ and considering the Lagrangian formulation of motion (d). Trajectories are obtained by integrating the horizontal displacements for each time step (plan view) (e). Catchment areas are estimated by circumscribing the surface origins of particles (f). 
particle is stored and the displacement for the preceding day is calculated and a new particle is introduced that starts to rise from the trap at this day. This procedure is repeated until the particles reach the surface or, in the case of the first trap interval, the velocity data registration started and no earlier recordings are available. Connecting the stored positions of one particle shows its trajectory from the surface to the trap. For every day of the trap deployment one trajectory is calculated. Combining the trajectories of particles for each day summarizes the paths of particles from the surface to the trap for a trap interval. Figure 1e shows a plan view of these particle trajectories, all of which are converging at the trap position. Circumscribing the surface positions of all particles then shows the estimated catchment area at the sea surface (Fig. 1f).

The presented results for the catchment areas have to be considered rough estimates of most probable catchment areas. A number of assumptions and simplifications have been made that contribute to the error of this estimate, such as the assumptions of the spatial homogeneity of the velocity field around the traps, averaging of the velocity fields, both in time and in the vertical layers and the assumption of a constant sinking speed of the particle. The latter includes the simplification that the vertical motion of the water itself is neglected. Further error is introduced by the accuracy of the current measurements.

The data used in this work are public and may be accessed via the German JGOFS project data management (http://www.ifm.uni-kiel.de/jgofs/dm). The method presented in this work may be applied to moored sediment traps in general if sufficient data of the velocity field at (and around) the mooring site are available. The modeling was performed with the technical computing language Matlab from The MathWorks Inc.; the script files and functions are available on request from the corresponding author.

\section{Results}

A representation of the simulated trajectories of individual particles sinking at $100 \mathrm{~m} \mathrm{~d}^{-1}$ (standard run) into traps at 500 m, 1000 m, $2000 \mathrm{~m}$ and $3500 \mathrm{~m}$ is shown in Figure 2. Each line shows the most probable path of a particle that is collected by the trap on a given day. Therefore, all trajectories end at the position of the trap and their starting points represent the most probable source region at the sea surface for the constant sinking speed of $100 \mathrm{~m} \mathrm{~d}^{-1}$. Changes of the direction of trajectories are caused by the different directions of the horizontal flow field in different depth layers and/or temporal changes of the velocity within a depth layer.

The spatial distribution of the particle origins at the sea surface relative to the position of the traps is shown in Figure 3. This representation is obtained by connecting the starting points of the individual particle trajectories shown in Figure 2. Particles collected by the deepest trap originated from many hundreds of kilometers away. The maximum distance between the region of particle production and the trap position increases with the 

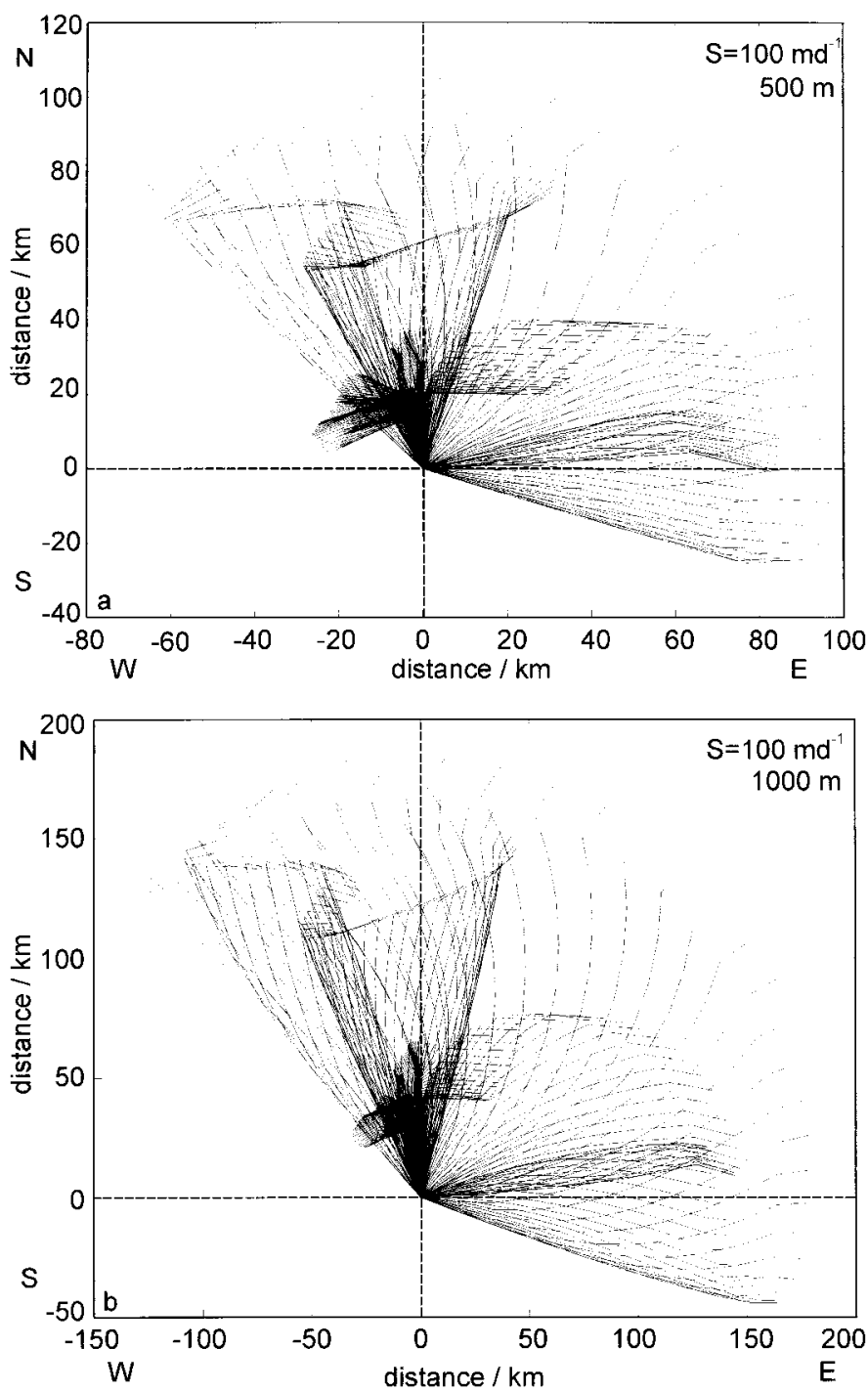

Figure 2. Trajectories of particles intersecting with the sediment traps deployed at $47 \mathrm{~N}, 20 \mathrm{~W}$ in $500 \mathrm{~m}$ (a), $1000 \mathrm{~m}$ (b), $2000 \mathrm{~m}$ (c) and $3500 \mathrm{~m}$ (d) depth. Velocity data from July 1994 to July 1995 were used and a sinking rate of $100 \mathrm{~m} \mathrm{~d}^{-1}$ was assumed. The trajectories are projected on a plane parallel to sea surface.

deployment depth of the trap (see Table 2). The maximum lateral displacement between the origin at the sea surface and the trap deployed in $3500 \mathrm{~m}$ is greater than $500 \mathrm{~km}$. This is in good agreement with the results presented by Siegel and Deuser (1997) for the Sargasso Sea near Bermuda. 

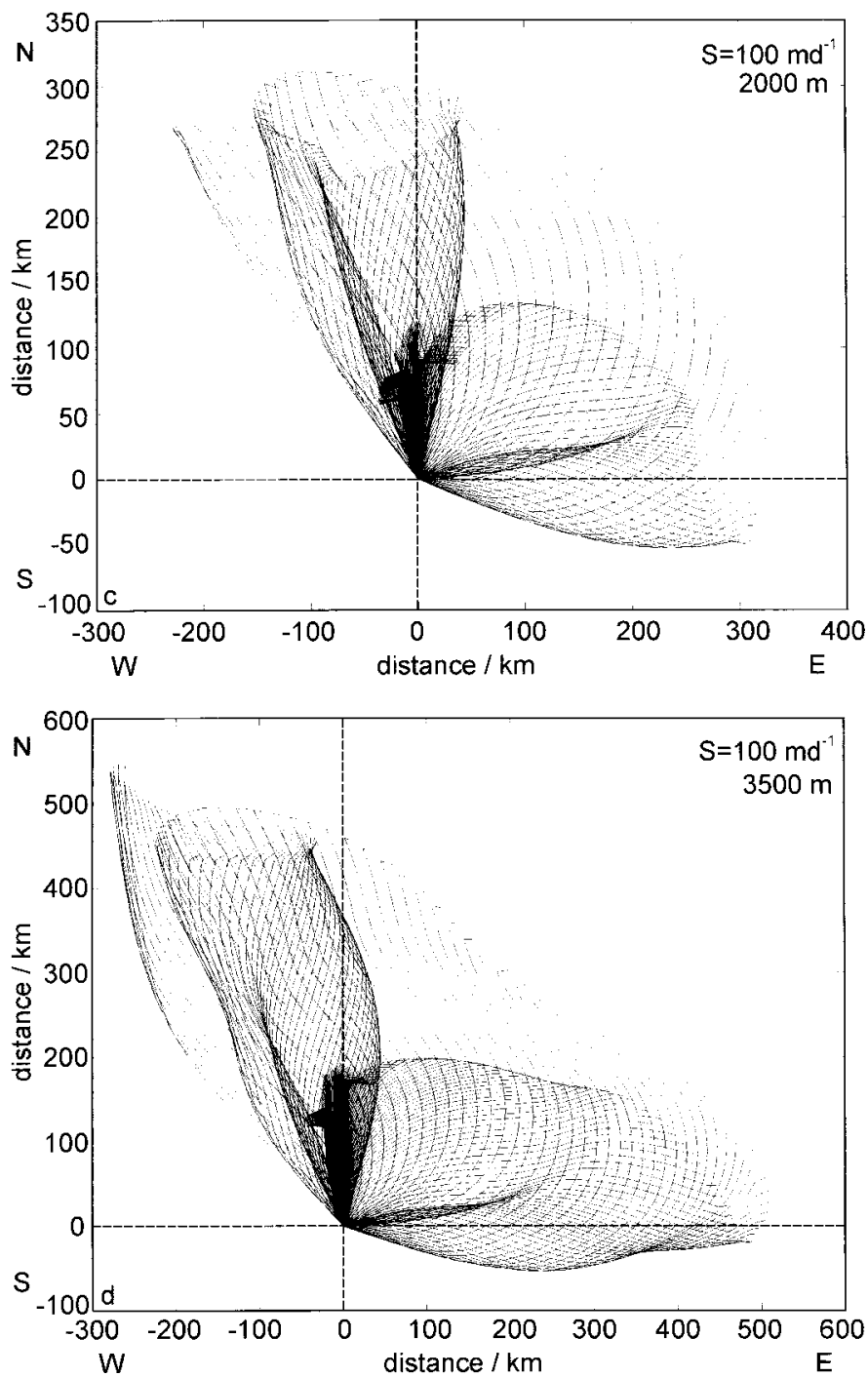

Figure 2. (Continued)

The effect of the sinking speed on the extent of the catchment area and the distance between catchment area and trap are shown in Figure 4. For this comparison additional experiments with sinking speeds of 50 and $200 \mathrm{~m} \mathrm{~d}^{-1}$, respectively, were conducted. While the shapes of the catchment areas show evident similarities due to the assumption that the characteristics of the velocity field are uniform throughout the whole region, the extensions of the areas are quite different. The catchment area for the trap in $3500 \mathrm{~m}$ depth is located up to $1000 \mathrm{~km}$ north ( $800 \mathrm{~km}$ east) of the trap position for an assumed particle sinking 


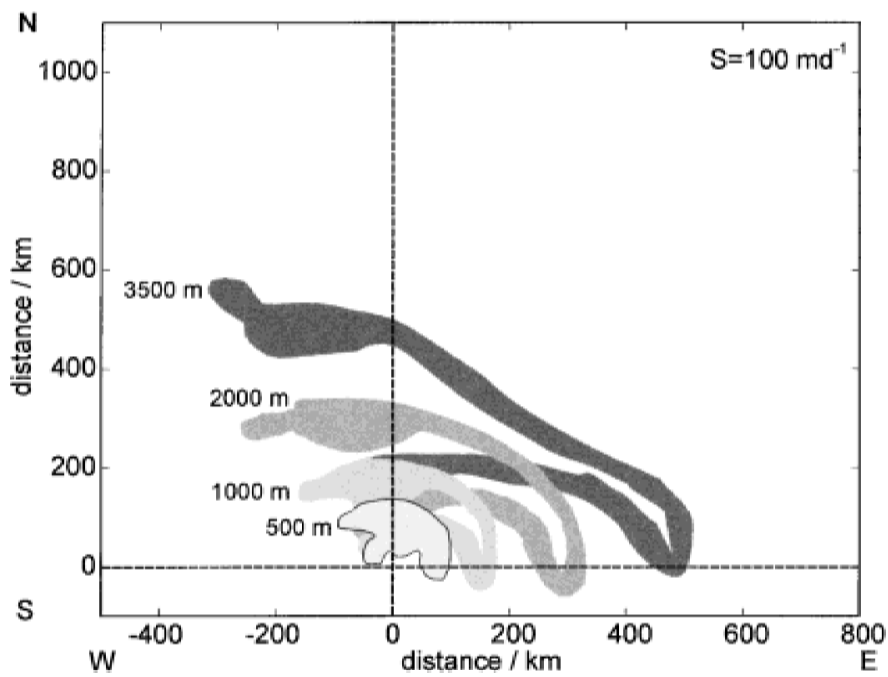

Figure 3. Catchment areas of sediment traps deployed at $47 \mathrm{~N}, 20 \mathrm{~W}$ in $500 \mathrm{~m}, 1000 \mathrm{~m}, 2000 \mathrm{~m}$ and $3500 \mathrm{~m}$ depth from July 1994 to July 1995 . Assumed particle sinking rate $100 \mathrm{~m} \mathrm{~d}^{-1}$. Catchment areas are shown relative to the position of the mooring $(0,0)$.

speed of $50 \mathrm{~m} \mathrm{~d}^{-1}$, whereas the catchment area for the same trap is located only up to $350 \mathrm{~km}$ north (300 km east) of the trap for particles with an assumed sinking speed of $200 \mathrm{~m} \mathrm{~d}^{-1}$. If the sinking speed of the particles is low, the extension of the probable catchment area is bigger and vice versa (Table 2). As we might expect that real traps sample particles with a variety of different sinking speeds, real catchment areas for a given trap depth might be looking much more like a superposition of the individual catchment areas for a given trap depth shown in Figures 3, 4a and 4b.

A comparison of the interannual variability of estimated catchment areas of the trap deployed in $500 \mathrm{~m}$ depth is shown in Figure 5. The assumed sinking speed was $100 \mathrm{~m} \mathrm{~d}^{-1}$. The distances between the trap location and the catchment areas in all years are of the same order. There are no significant differences in the size of the catchment area between the years, but differences in the most probable production region are evident, showing an overlap of about $30 \%$ for the years 1993 to 1995 . This means that the location of the catchment area depends on the dominating currents and can be shifted in space for different years.

\section{Discussion}

\section{a. A comparison of different approaches}

There is no way to determine the true size and shape of the statistical funnel and the catchment areas at the sea surface for a given trap nor its position with respect to the trap 
Table 2. Comparison of the maximum spatial extension of the catchment areas calculated for different sinking rates $\left(50 \mathrm{~m} \mathrm{~d}^{-1}, 100 \mathrm{~m} \mathrm{~d}^{-1}\right.$ and $\left.200 \mathrm{~m} \mathrm{~d}^{-1}\right)$ and traps deployed at Biotrans site in different depths $(500 \mathrm{~m}, 1000 \mathrm{~m}, 2000 \mathrm{~m}$ and $3500 \mathrm{~m})$.

$\begin{array}{cccc}\begin{array}{c}\text { Sinking } \\ \text { rate } \\ \mathrm{m} \mathrm{d}^{-1}\end{array} & \begin{array}{c}\text { Depth of } \\ \text { the trap } \\ \mathrm{m}\end{array} & \begin{array}{c}\text { Extension in } \\ \text { north }(+)-\operatorname{south}(-)\end{array} & \begin{array}{c}\text { Extension in } \\ \text { east }(+)-\operatorname{west}(-) \\ \text { direction } \\ \mathrm{km}\end{array} \\ 50 & 500 & \mathrm{~km} & 325(+175,-150) \\ & 1000 & 250(+200,-50) & 600(+350,-250) \\ & 2000 & 350(+300,-50) & 800(+600,-200) \\ 100 & 3500 & 525(+500,-25) & 1300(+800,-400) \\ & 500 & 1000(+1000,) & 180(+100,-80) \\ & 1000 & 250(+200,-50) & 350(+200,-150) \\ & 2000 & 375(+325,-50) & 570(+320,-250) \\ & 3500 & 600(+550,-50) & 800(+500,-300) \\ & 500 & 80(+60,-20) & 90(+50,-40) \\ & 1000 & 130(+110,-20) & 180(+100,-80) \\ & 2000 & 250(+200,-50) & 325(+175,-150) \\ & 3500 & 350(+300,-50) & 550(+300,-250)\end{array}$

(Deuser et al., 1990) since this would require a detailed knowledge of the time-varying three-dimensional flow fields around the sediment trap mooring and a realistic estimate of the biomass weighted spectrum of the sinking speed of the particles intercepting the trap. A variety of statistical approaches has been used to roughly estimate the size, shape and orientation of the statistical funnel for a given particle flux study (Deuser $e t$ al., 1988; 1990; Siegel et al., 1990; Siegel and Deuser, 1997). In our study, we suggest a simple approach that easily can be adopted to any particle flux study that has access to either one dimensional flow field data from current meters or ADCP observations or to other independent estimates of the flow field around moored sediment traps (ship based ADCP, high resolution model data; Determann et al., 1999). The approach enables time-resolving estimates of catchment areas for traps from different deployment depths. For our study site and a given year, these catchment areas were significantly displaced from the mooring site and from each other. Catchment areas during a given time period, like the spring bloom particle flux peak (Fig. 6) i.e. can be separated by several hundred kilometers. Catchment areas for a given trap depth and season can vary for different years.

Our approach is based on the simplification that the horizontal velocity field is homogeneous and that one dimensional current measurements can be used for estimates of particle trajectories and catchment areas. In view of the well known importance of mesoscale eddies and similar structures in the northeast Atlantic (e.g., Robinson et al., 

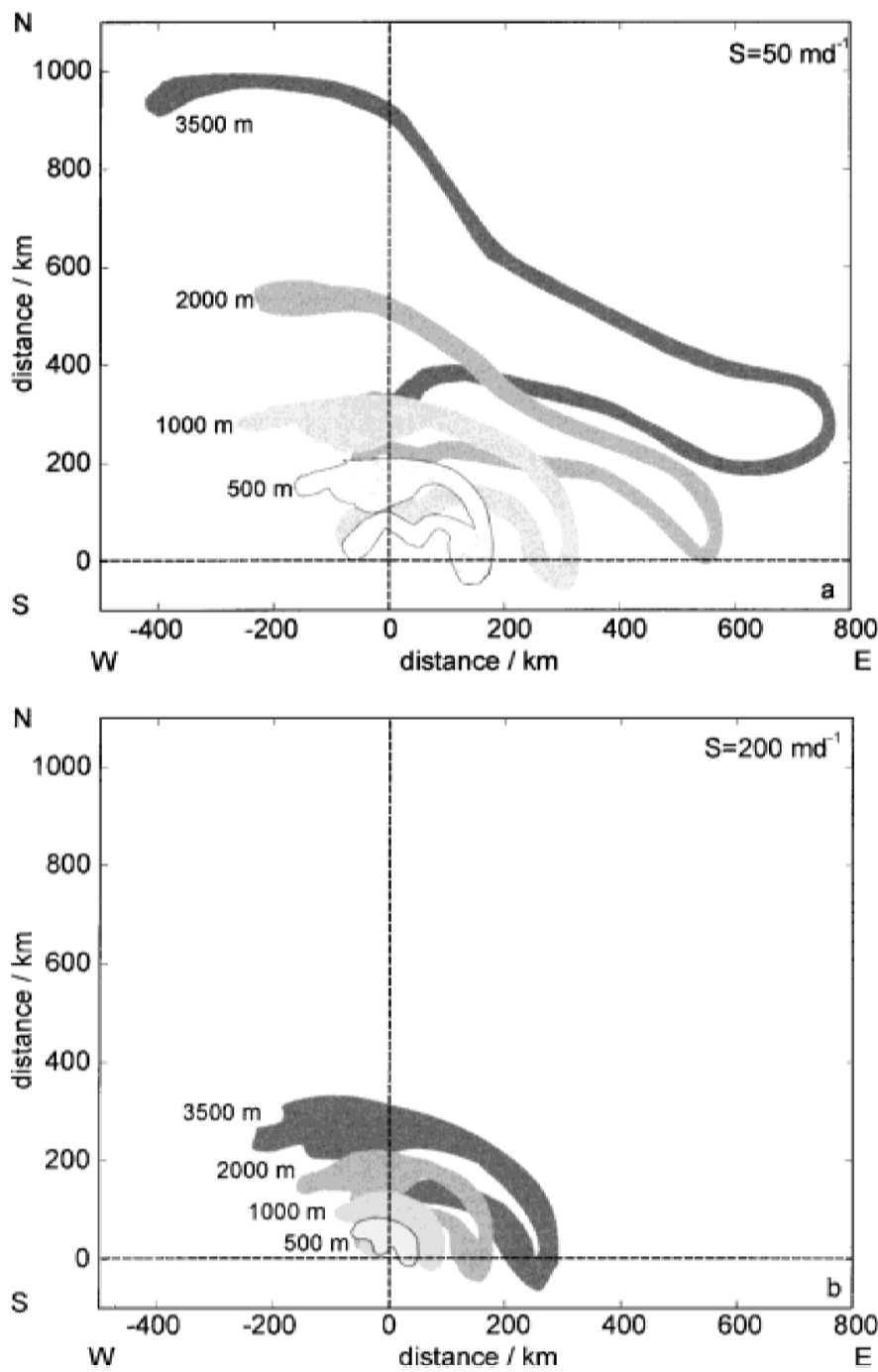

Figure 4. Catchment areas as a function of the assumed sinking speed of particles. Catchment areas of sediment traps deployed at $47 \mathrm{~N}, 20 \mathrm{~W}$ in $500 \mathrm{~m}, 1000 \mathrm{~m}, 2000 \mathrm{~m}$ and $3500 \mathrm{~m}$ depth between July 1994 and July 1995 are shown. Particle sinking rates were $50 \mathrm{~m} \mathrm{~d}^{-1}$ (a) and $200 \mathrm{~m} \mathrm{~d}^{-1}$ (b). Catchment areas are shown relative to the position of the mooring $(0,0)$.

1993), one might speculate that this simplification implies a strong overestimate of the extent of the catchment area and the distance between catchment area and sediment trap. In the following we compare our results with the horizontal displacement of sinking particles (the possible catchment areas) calculated with the method of Siegel and Deuser (1997). 


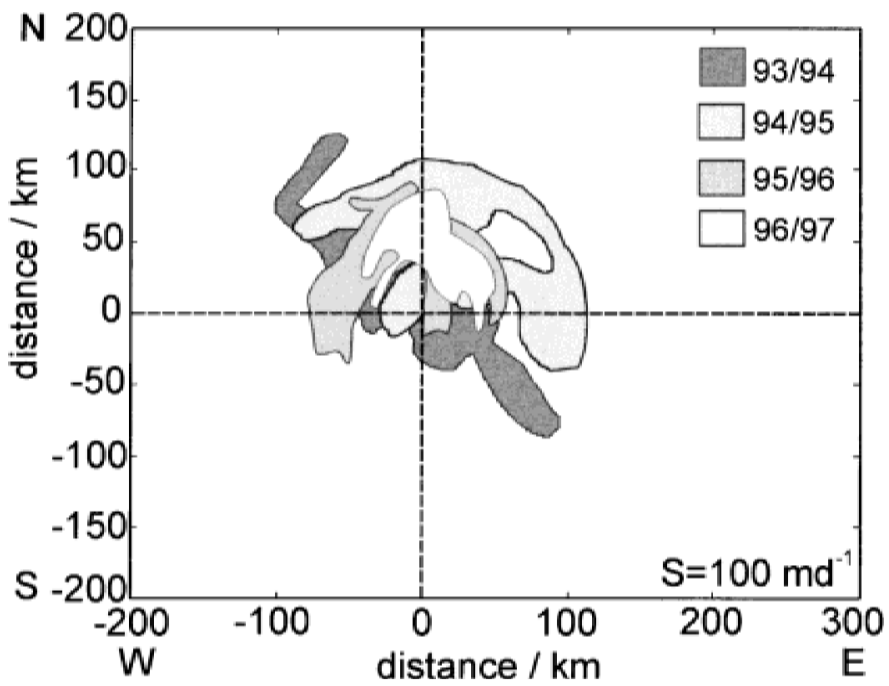

Figure 5. Interannual variability of the catchment areas for the trap deployed at $47 \mathrm{~N}, 20 \mathrm{~W}$ in $500 \mathrm{~m}$ depth. Catchment area for the deployment period 1993/1994 (grey), 1994/1995 (light grey), 1995/1996 (dark grey) and for the deployment period 1996/1997 (white) are shown. The assumed particle sinking speed was $100 \mathrm{~m} \mathrm{~d}^{-1}$.

There a Lagrangian integral length scale $L$ was used, which is defined as

$$
L=2 \cdot\left[K e \cdot \tau \cdot T_{i}-K e \cdot \tau^{2} \cdot\left(1-\exp \left(-T_{i} / \tau\right)\right)\right]^{1 / 2}
$$

where $T_{i}$ is the time period in the water column, $\tau$ is the integral time scale (time period after which the particle velocities become de-correlated) and $\mathrm{Ke}$ is the kinetic energy. Siegel and Deuser (1997) did not differentiate between the meridional and zonal components of the velocity field. For our calculations we decided to divide the kinetic energy and integral length scales into meridional and zonal components and applied an integral time scale $\tau$ of 20 days for all depths (Rossby et al., 1986). Vertical profiles of the mean kinetic energy and fluctuating kinetic energy calculated from observed horizontal currents were used to obtain the horizontal advection of individual sinking particles (Waniek and Zeitzschel, 2001). Finally, only vertical variations in the horizontal velocity field (kinetic energy) were considered. This assumes that the statistics of the velocity field does not change significantly in the region.

Distances of the possible catchment areas relative to the sediment trap calculated with the method described in this study and with the formulation of Siegel and Deuser (1997) for the time period of the spring bloom in year 1997 are shown in Figure 7. The horizontal distances between the catchment area and the sediment trap are plotted as a function of time. The distances calculated with both methods are comparable; we do not see any systematic overestimation of the distances calculated with our method. In detail, some 
differences are evident between the two simulations. These differences are partly due to a different degree of averaging of the input data that are used in the calculations. In our Lagrangian approach we used daily mean velocity data, while the original, high resolution velocity data (two hourly) were used for calculation of the mean and fluctuating kinetic energy needed to obtain the integral length scales $L_{x}$ and $L_{y}$. In addition, the approach of Siegel and Deuser (1997) does not account for changes in the direction of the fluctuating part of the horizontal currents. The method of Siegel and Deuser (1997) does not provide detailed information on the geographic position of the catchment area relative to the trap mooring. Their catchment areas are circles with the radius $L$, the center of these circles is shifted relative to the trap position by the mean flow only. Our method enables a more detailed description of the real position of the catchment area relative to the mooring. This is of great importance if estimates of catchment areas are used in combination with data on the horizontal distribution of phytoplankton biomass and productivity in the surface layer, e.g. from remote sensing of ocean color.

\section{b. Mesoscale variability and the interpretation of sediment trap results}

Particle flux observations are typically interpreted in a basically one-dimensional sense. It is assumed that sediment traps at different water depths sample particles from an identical source region which is expected to be more or less above the mooring site. In this simplified view particle flux is expected to decrease with depth due to remineralization at mid-depth (Martin et al., 1987) and particle flux patterns (highs and lows) are expected to propagate from the surface to the bottom of the ocean. This approach has been applied to estimate approximate sinking speeds from the temporal co-occurence of, or time lags between, peak maxima at different depths (e.g. Newton et al., 1994). The detailed interpretation of the decrease of particle flux with depth (Martin et al., 1987) or the observed change in composition with depth (e.g. Knappertsbusch and Brummer, 1995; Lundgreen and Duinker, 1998; Kuss and Kremling, 1999) implies that either the catchment areas at the surface are identical or at least that the wider area around the mooring that comprises all individual catchment areas is characterized by homogeneity of plankton biomass, composition and particularly primary export flux from the productive surface.

We have demonstrated that catchment areas of sediment traps from different depths at the Biotrans site are by no means identical. This, however, matters only if there is evidence for mesoscale variability of the temporal patterns, absolute magnitude and the composition of the primary export flux (export production) from the productive layer. There is a very limited number of studies which have tried to test such a hypothesis directly, mainly since the use of drifting sediment traps is hampered by a number of methodological obstacles (hydrodynamics, Gust et al., 1992, 1994; swimmers, Michaels et al., 1990; Gardner, 1999). One of the few examples of mesoscale-resolving estimates of particle export, though for the much less seasonal Sargasso Sea and with an indirect approach (Buesseler et al., 1994), 


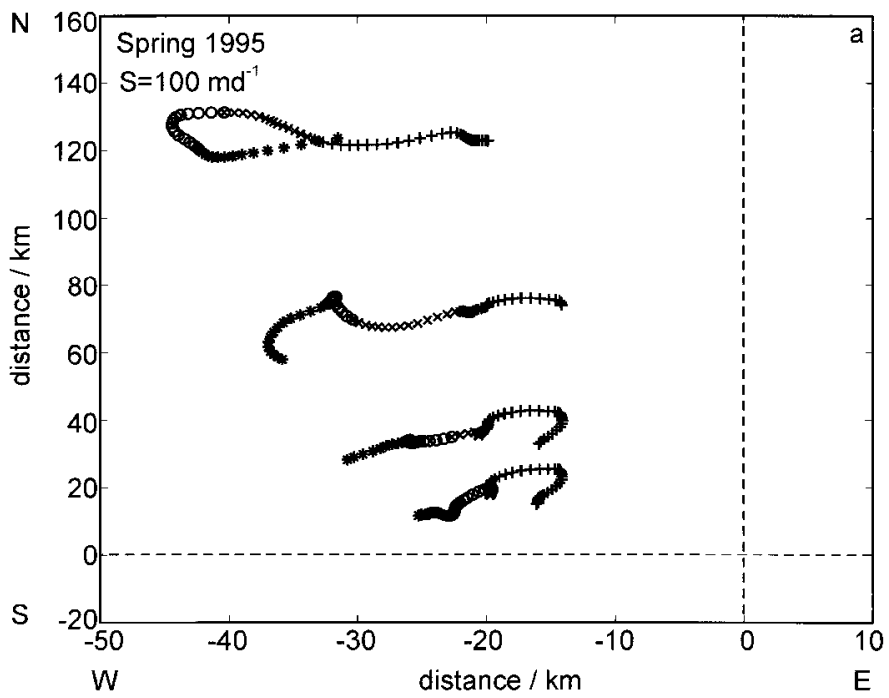

Figure 6. Detailed presentation of the catchment areas during the spring bloom periods of 1995 to 1997. Different symbols represent the following sampling intervals: (a) 09.03.-23.03.95 (*), 23.03.-06.04.95 (o), 06.04.-20.04.95 (x) and 20.04.-18.05.95 (+); (b) 02.03.-17.03.96 (*), 17.03.-01.04.96 (o), 01.04.-16.04.96 (x), 16.04.-01.05.96 (+) and 01.05.-16.05.96 ( $\square$ ); (c) 02.03.-30.03.97 (*), 30.03.-13.04.97 (o), 13.04.-27.04.97 (x) and 27.04.-11.05.97 (+). The assumed particle sinking speed was $100 \mathrm{~m} \mathrm{~d}^{-1}$. Note different scales.

suggests significant mesoscale differences of surface ocean thorium deficits as well as particle export.

Albeit the strong seasonal signal in plankton biomass (Heinrich, 1962; Colebrook, 1982; Esaias et al., 1986) and nutrient concentrations are characteristic for the temperate northeast Atlantic, mesoscale variability in winter nutrient stocks (McGillicuddy et al., 1995a) and spring time mixed layer depth development (Taylor and Stephens 1993; Townsend et al., 1994) contribute significantly to observed patterns of plankton biomass and composition (Robinson et al., 1993; Lochte et al., 1993).

During winter and early spring mesoscale-varying vertical structures of density, sea surface temperature and heat content of the upper ocean may respond differently to the same mesoscale atmospheric forcing (wind speed, humidity and air temperature). This results in variable initial spring mixed layer depth, pre-spring nutrient content of the productive layer and sensitivity to storm perturbation of the developing spring system (Koeve et al., 2000). Similarly, mesoscale updoming of water, i.e. in the center of cyclonic/cold water eddies during summer, might provide more new nutrients and hence support additional new production compared to surrounding waters (Falkowski et al., 1991; McGillicuddy and Robinson 1997; Williams and Follows, 1998).

Observations on mesoscale variability of plankton in the open ocean are still scarce and do not resolve the question of whether time integrated new and export production (e.g. over 

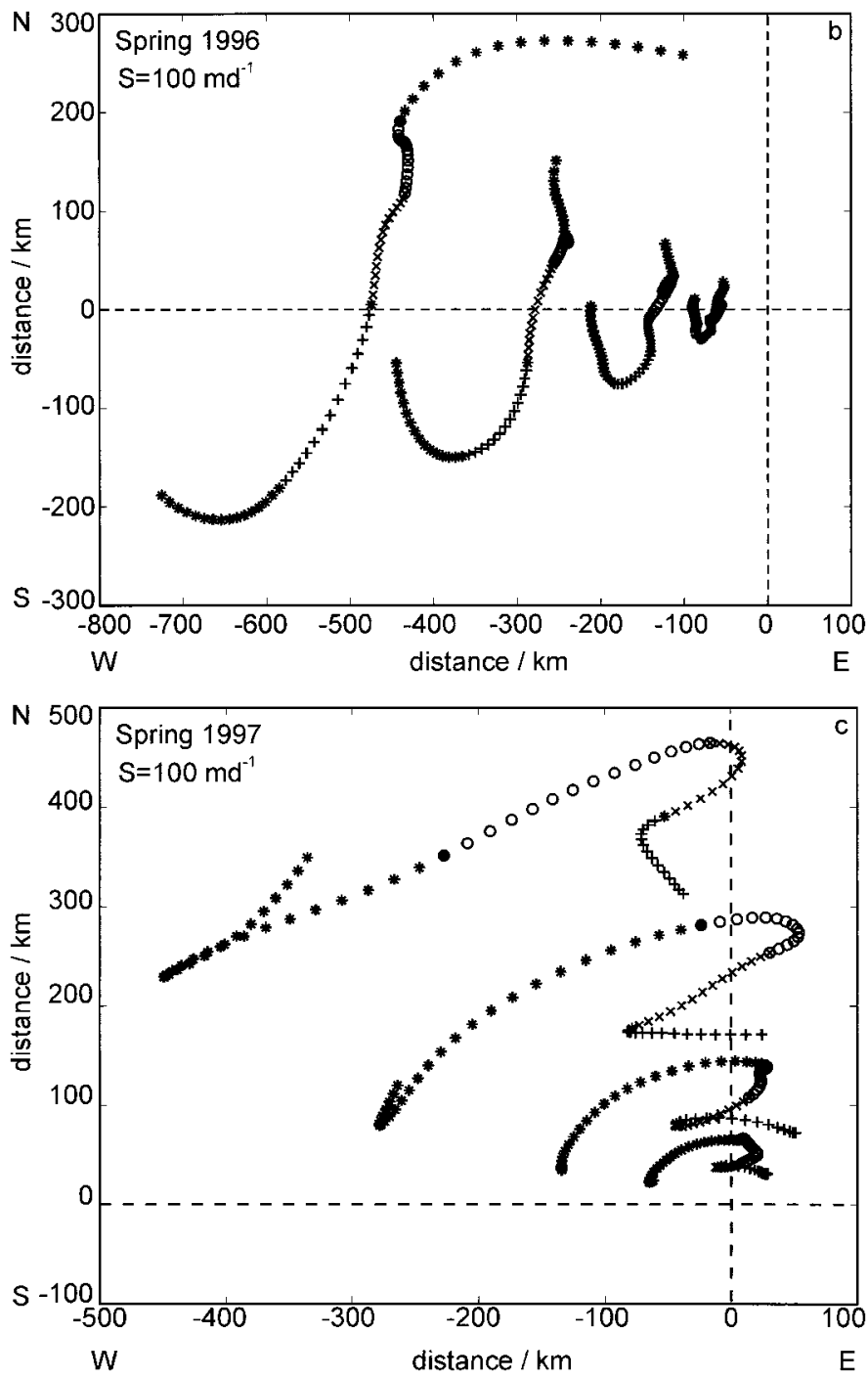

Figure 6. (Continued)

the spring bloom) shows significant variations. Observations, however, enable the estimate of typical spatial length scales of plankton patchiness. A number of such data sets exist from the Biotrans region for the spring season (April to June) and will be further evaluated.

The first example is from a study carried out during April and May 1985 (Kupfermann et al., 1986; Mittelstaedt, 1987; Lochte and Pfannkuche, 1987). Early in this study, overall surface phosphate concentrations of about $0.5 \mu$ mole $\mathrm{dm}^{-3}$ (Kupferman et al., 1986) indicated unmodified late winter time conditions (Koeve, 2000). Slightly elevated nutrient 


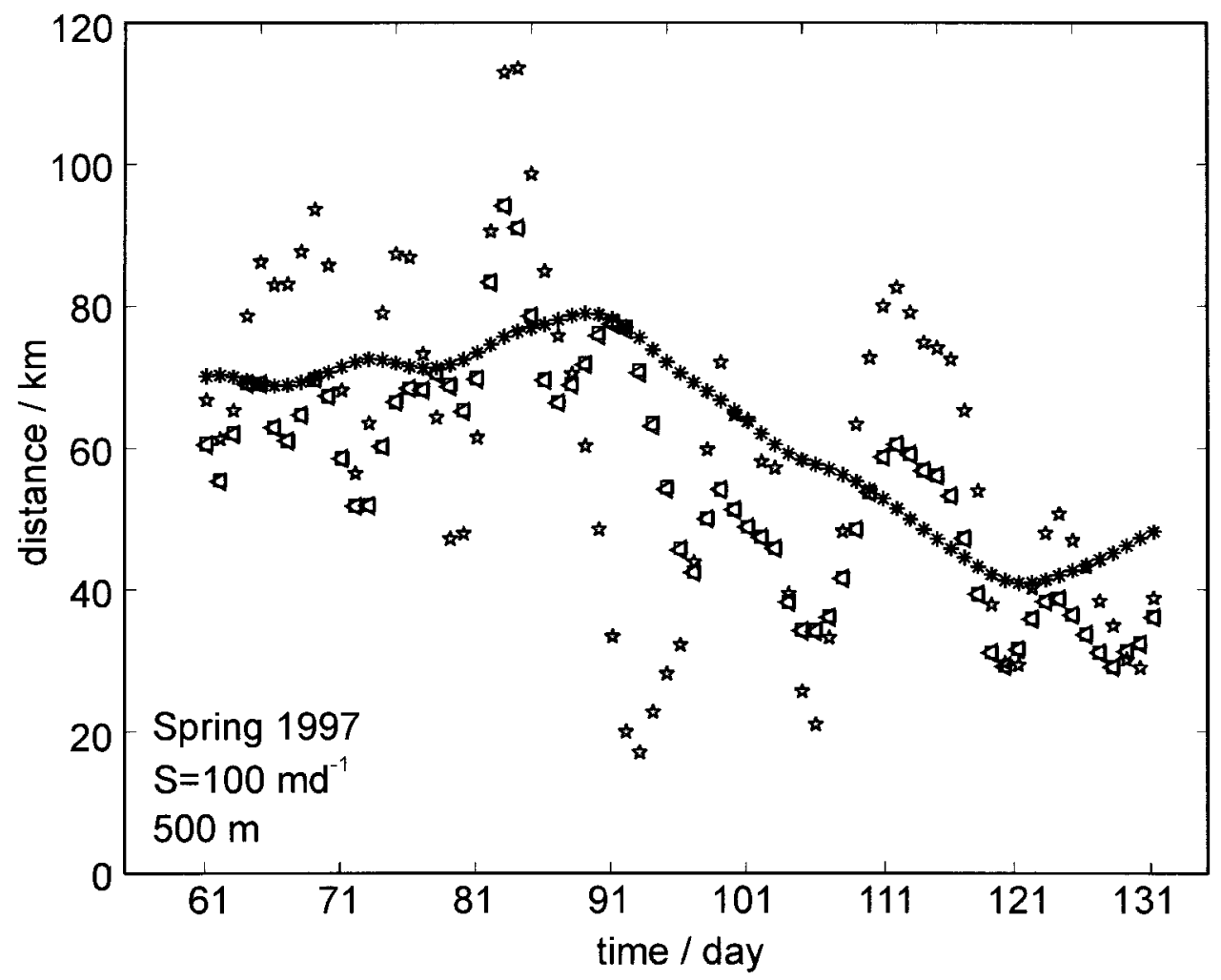

Figure 7. Comparison of the distance between the catchment areas and the sediment trap as based on calculations performed with our method $(*)$ and with the method described by Siegel and Deuser (1997, stars), where $L_{x}=L_{y}$ and $\tau=20$ day. Estimates for the spring bloom period in 1997 (2.03. to 11.05.) are shown for sediment trap deployed in $500 \mathrm{~m}$ depth. A particle sinking velocity of $100 \mathrm{~m} \mathrm{~d}^{-1}$ was assumed. Additionally absolute distances to the sediment trap calculated with variable $\tau$ and $L_{x}, L_{y}$ using time series as presented by Waniek and Zeitzschel, (in rev., triangles) and for the case $\tau=20$ days for each component and $L_{x}, L_{y}$ calculated from the registrations (squares) are shown.

concentrations, however, were observed within a cold core eddy having surface temperatures that were about $1^{\circ} \mathrm{C}$ colder than ambient waters. About a month later surface nutrient concentrations within the core had decreased below $2 \mu$ mole $\mathrm{dm}^{-3}$ and were significantly lower if compared to ambient waters (Lochte and Pfannkuche, 1987). Surface chlorophyll $a$ concentrations from within the core were about three times as large as those from outside the cold core ring. Stronger stratification in general and a more stable and more shallow mixed layer in particular are obvious within the cold core eddy (Kupfermann et al., 1986; Mittelstaedt, 1987). In accordance with Sverdrup's theory (Sverdrup, 1953) this allows for a faster propagation of the spring bloom within the eddy. We speculate that the spring bloom sedimentation event from within the cold core ring is expected to have occurred 
earlier compared to that of ambient waters. The diameter of the cold core was about $70 \mathrm{~km}$ and the distance between core margin and ambient water about $40 \mathrm{~km}$ (estimated after data in Lochte and Pfannkuche, 1987). Significant variations in the timing of the beginning and end of the spring bloom can be expected on length scales of about $100 \mathrm{~km}$.

Observations with spaceborne altimetry (Robinson et al., 1993), airborne XBT and Lidar (Yoder et al., 1993) and 3D-mesoscale modeling (McGillicuddy et al., 1995a,b) have provided insight into mesoscale variations during the North Atlantic Spring Bloom Experiment in 1989 (Ducklow and Harris, 1993) at the Biotrans Site. Surface temperature structures from AXBT are characterized by lows and highs with typical differences of about $0.5^{\circ} \mathrm{C}$ (Robinson et al., 1993) while core/ambient comparison of chlorophyll fluorescence shows differences of up to a factor of two. The typical diameter of such structures is about 40 to $50 \mathrm{~km}$.

Detailed studies of mesoscale variability of phytoplankton biomass at the Biotrans site have been conducted in 1990 (Savidge et al., 1992). During April overall conditions were characterized by weak stratification and low chlorophyll $a$ concentrations (about 0.2 to $0.5 \mu \mathrm{g} / \mathrm{l}$ chlorophyll $a$ ), except for a distinct area with elevated chlorophyll concentrations up to $1.5 \mu \mathrm{g} / \mathrm{l}$ chlorophyll $a$. Maximum differences (factor 7 to 9 ) were observed on distances of about $100 \mathrm{~km}$. Observations from the mesoscale survey and from a drogue experiment carried out over the season indicate earlier enhancement of chlorophyll $a$ in waters characterized by stronger and more shallow stratification within cold water structures compared to an anticyclonic warm water structure.

From the above we conclude that strong mesoscale variations of phytoplankton biomass and most likely also of primary particle export are a dominant feature during spring phytoplankton blooms in the Biotrans region. The typical length scale of this variability is in the order of 50 to $100 \mathrm{~km}$. In the following we discuss the spring time horizontal distribution of the production areas of particles sampled by sediment traps deployed at $500 \mathrm{~m}, 1000 \mathrm{~m}, 2000 \mathrm{~m}$ and $3500 \mathrm{~m}$ depths (Fig. 6). We have grouped data from the standard run (sinking velocity of $100 \mathrm{~m} \mathrm{~d}^{-1}$ ) according to the sampling intervals of the sediment traps. During each of the spring periods differences in the geographical location of the production regions of particles relative to the sediment traps are clearly evident. For example, during the sample interval from 9.3. to 23.3.1995 (marked by stars in Fig. 6a) the $500 \mathrm{~m}$ sediment trap collected particles from a production area maximum $25 \mathrm{~km}$ west and $20 \mathrm{~km}$ north of the trap. During the same sampling interval the sediment trap moored in $3500 \mathrm{~m}$ depth collected particles originating from a region $125 \mathrm{~km}$ north and $30-40 \mathrm{~km}$ west of the mooring position (Fig. 6a). Eventually assemblages of sinking particles that have been sampled during the same time period but at different depths have left the surface of the ocean up to $100 \mathrm{~km}$ apart from each other, that is from epipelagic systems that may have been in different stages of the seasonal cycle (e.g. pre-bloom, bloom, post-bloom) during that time. Furthermore, the time series of collection rates of a given sediment trap (e.g. in $1000 \mathrm{~m}$ water depth) do not necessarily reflect the time course of particle export 
from the local surface ocean. Over the spring season the particle production region of a given sediment trap moves over distances of $10 \mathrm{~km}(500 \mathrm{~m})$ to $25 \mathrm{~km}$ (3500 m trap).

\section{Conclusions}

The present study makes specific statements about the possible origin of the particle collected at the JGOFS mooring site L2 at 47N, 20W in the northeast Atlantic. Specific to L2, we show that the surface waters located northeast and northwest of the mooring are the most probable locations of particle formation and export. Our results for sediment trap sampling are general and can be easily extended to moored trap studies at other geographic sites, if current meter registrations are available. We agree with the conclusion of Siegel and Deuser (1997), that the term vertical particle flux does not describe correctly the particle motion on the way from surface to the deep ocean.

We conclude that the detailed interpretation of particle flux data is very much complicated by the three-dimensional displacement of sinking particles; i.e., interaction of horizontal advective motions with sinking particles. Care should be taken not to overstress short-term patterns observed in particle flux studies. This is particularly true for regions with strong and systematic gradients in the epipelagic zone (e.g., at persistent hydrographical structures like shelf break fronts). The present results imply that the interaction of horizontal advective motions with sinking particles should be considered in the interpretation of sediment trap measured particulate fluxes. The interpretation of sediment trap data requires not only the analysis of material found in the trap but also knowledge of the life history of the particles prior to their collection and the flow through which they traversed.

Acknowledgments. This study is a contribution to the German JGOFS North Atlantic Program and was supported by the German Ministry of Education and Research (BMBF) under contract BEO 03F01060A and 03F0202D. The authors sincerely thank Stefan Will and Johannes Petersen for technical support during the study. This work benefited from stimulating discussions within the Biogeochemistry Working Group at IfM, in particular with Andreas Oschlies. Special thanks are addressed to Paul Kähler, Klaus Kremling and Bernt Zeitzschel for comments and discussion. We would like to thank two anonymous reviewers for stimulating comments.

\section{REFERENCES}

Alldredge, A. L. and C. Gotschalk. 1988. In situ settling behavior of marine snow. Limnol. Oceanogr., 33, 339-351.

Alldredge, A. L. and M. W. Silver. 1988. Characteristics, dynamics and significance of marine snow. Progr. Oceanogr., 20, 41-82.

Allen, J. T. and D. A. Smeed. 1996. Potential vorticity and vertical velocity at the Iceland-Færæs Front. J. Phys. Oceanogr., 26, 2611-2634.

Antia, A. N., E. Bauerfeind, B. von Bodungen and U. Zeller. 1993. Abundance, encystment and sedimentation of acantharia during autumn 1990 in the East Greenland Sea. J. Plankton Res., 15, $99-114$.

Antia, A. N., B. v. Bodungen and R. Peinert. 1999. Particle flux across the mid-European continental margin. Deep-Sea Res. I, 46, 1999-2024. 
Asper, V. L. 1987. Measuring the flux and sinking speed of marine snow aggregates. Deep-Sea Res., $34,1-17$.

1996. Particle flux in the ocean: Oceanographic tools, in Particle Flux in the Ocean, V. Ittekkot, P. Schäfer, S. Honjo and P. J. Depetris, eds., SCOPE 57, J. Wiley and Sons, NY, 367 pp.

Asper, V. L., W. G. Deuser, G. A. Knauer and S. E. Lohrenz. 1992. Rapid coupling of sinking particle fluxes between surface and deep ocean waters. Nature, 357, 670-672.

Berger, W. H. and D. J. W. Piper. 1972. Planktonic foraminifera: differential settling velocity, dissolution and redeposition. Limnol. Oceanogr., 17, 275-287.

Bienfang, P. K. 1980. Phytoplankton sinking rates in oligotrophic waters off Hawaii, USA. Mar. Biol., 61, 69-77.

Billet, D. S. M., R. S. Lampitt, A. L. Rice and R. F. C. Mantoura. 1983. Seasonal sedimentation of phytoplankton to the deep sea benthos. Nature, 302, 520-522.

Bower, A. S. and T. Rossby. 1989. Evidence of cross-frontal exchange processes in the Gulf Stream based on isopycnal RAFOS float data. J. Phys. Oceanogr., 19, 1177-1190.

Bruland, K. W. and M. W. Silver. 1981. Sinking rates of fecal pellets from gelatinous zooplankton (salps, pteropods, doliolids). Mar. Biol., 63, 295-300.

Buesseler, K. O., A. F. Michaels, D. A. Siegel and A. H. Knap. 1994. A three-dimensional time-dependent approach to calibrating sediment trap fluxes. Global Biogeochem. Cycles, 8, 179-193.

Colebrook, J. M. 1982. Continuous plankton records: seasonal variations in the distribution and abundance of plankton in the North Atlantic Ocean and the North Sea. J. Plankt. Res., 4, 435-462.

Colin de Verdiere, A., H. Mercier and M. Arhan. 1989. Mesoscale variability transition from the Western to the Eastern Atlantic along 48N. J. Physical Oceanogr., 19, 1149-1170.

Determann S., M. J. Rueda and S. Neuer. 1999. Influence of the ocean circulation on the sediment trap measurements at the ESTOC-station. Geophys. Res. Abstracts, 1, 407.

Deuser, W. G., F. E. Muller-Karger, R. H. Evans, O. B. Brown, W. E. Esaias and G. C. Feldman. 1990. Surface ocean color and deep ocean carbon flux: how close connection? Deep-Sea Res., 37, 1331-1343.

Deuser, W. G., F. E. Muller-Karger and C. Hemleben. 1988. Temporal variations of particle fluxes in the deep subtropical and tropical North Atlantic: Eulerian versus Lagrangian effects. J. Geophys. Res., 93, 6857-6862.

Deuser, W. G. and E. H. Ross. 1980. Seasonal change in the flux of organic carbon to the deep Sargasso Sea. Nature, 283, 364-365.

Deuser, W. G., E. H. Ross and R. F. Anderson. 1981. Seasonality in the supply of sediment to the deep Sargasso Sea and implications for the rapid transfer of matter to the deep ocean. Deep-Sea Res., 28, 495-505.

Ducklow, H. W. and R. P. Harris. 1993. Introduction to the JGOFS North Atlantic Bloom Experiment. Deep-Sea Res. II, 40, 1-9.

Esaias, W. E., G. C. Feldman, C. R. McClain and J. A. Elrod. 1986. Monthly satellite-derived phytoplankton pigment distribution for the North Atlantic Ocean basin. EOS, 67, 835-837.

Falkowski, P. G., D. Ziemann, Z. Kolberg and P. K. Bienfang. 1991. Role of eddy pumping in enhancing primary production in the ocean. Nature, 352, 55-58.

Fowler, S. W. and G. A. Knauer. 1986. Role of large particles in the transport of elements and organic compounds through the oceanic water column. Progr. Oceanogr., 16, 147-194.

Garçon, V., A. Oschlies, S. C. Doney, D. McGillicuddy and J. Waniek. 2001. The role of mesoscale variability on plancton dynamics. Deep-Sea Res. II, (in press). 
Gardner, W. D. 1999. Sediment trap technology and sampling in surface waters, in The Dynamic Ocean Carbon Cycle: A Midterm Synthesis of the Joint Global Ocean Flux Study, 1st International JGOFS Symposium, Villefrance Sur Mer, France, May 8-12, 1995 (in press).

Gill, A. E. 1982. Atmosphere-Ocean Dynamics, Academic Press, London, International Geophysics Series, 30, $662 \mathrm{pp}$.

Gust, G., B. R. E. Byrne, P. R. Betzer and W. Bowles. 1992. Particle fluxes and moving fluids: experience from synchronous trap collections in the Sargasso Sea. Deep-Sea Res., 39, 1071-1083.

Gust, G., A. F. Michaels, R. Johnson, W. G. Deuser and W. Bowles. 1994. Mooring line motions and sediment trap hydromechanics: In situ intercomparison of three common deployment designs. Deep-Sea Res. I, 41, 831-857.

Heinrich, A. K. 1962. The life histories of plankton animals and seasonal cycles of plankton communities in the ocean. J. Cons. Int. Explor. Mer, 27, 15-24.

Honjo, S. 1996. Fluxes of particles to the interior of the open oceans, in Particle Flux in the Ocean, SCOPE 57, J. Wiley \& Sons, NY, 91-145.

Knappertsbusch, M. and G.-J. A. Brummer. 1995. A sediment trap investigation of sinking coccolithophoridsin the North Atlantic. Deep-Sea Res., I, 42, 1083-1109.

Knauer, G. and V. Asper. 1989. Sediment trap technology and sampling, US GOFS Planning Report Number 10, 94 pp.

Koeve, W. 2000. Wintertime nutrients in the North Atlantic-I. New approaches and implications for estimates of seasonal new production. Mar. Chem. (submitted).

Koeve W., F. Pollehne, A. Oschlies and B. Zeitzschel. 2000. Storm induced convective transport of suspended matter during a spring bloom in the northeast Atlantic. Deep-Sea Res. I (submitted).

Kuenen, P. E. 1950. Marine Geology, John Willey and Sons, Inc., NY, 558 pp.

Kupferman, S. L., G. A. Becker, W. F. Simmons, U. Schauer, M. G. Marietta and H. Nies. 1986. An intense cold core eddy in the northeast Atlantic. Nature, 319, 474-477.

Kuss, J. and K. Kremling. 1999. Particle trace element fluxes in the deep northeast Atlantic Ocean. Deep-Sea Res. I, 46, 149-169.

Lochte, K., H. W. Ducklow, M. J. R. Fasham and C. Stienen. 1993. Plankton succession and carbon cycling at 47N 20W during the JGOFS North Atlantic Bloom Experiment. Deep-Sea Res., II, 40, 91-114.

Lochte, K. and O. Pfannkuche. 1987. Cyclonic cold-core eddy in the eastern North Atlantic. II. Nutrients, phytoplankton and bacterioplankton.Mar. Ecol. Prog. Ser., 39, 153-164.

Lundgreen, U. and J. C. Duinker. 1998. Seasonal variability of amino acid flux and composition of particulate matter in the northeast Atlantic at 47N-20W. Mar. Chem., 62, 307-323.

Martin, J. H., G. A. Knauer, D. M. Karl and W. W. Broenkow. 1987. VERTEX: carbon cycling in the northeast Pacific. Deep-Sea Res., 34, 267-285.

McGillicuddy, D. J., J. J. McCarthy and A. R. Robinson. 1995a. Coupled physical and biological modeling of the spring bloom in the North Atlantic (I): Model formulation and one dimensional bloom processes. Deep-Sea Res. I, 42, 1313-1357.

1995b. Coupled physical and biological modeling of the spring bloom in the North Atlantic (II): Three dimensional bloom and post bloom processes. Deep-Sea Res. I, 42, 1359-1398.

McGillicuddy, D. J. and A. R. Robinson. 1997. Eddy-induced nutrient supply and a new production in the Sargasso Sea. Deep-Sea Res. I, 44, 1427-1450.

Michaels, A. F., M. W. Silver, M. M. Gowing and G. A. Knauer. 1990. Cryptic zooplankton swimmers in upper ocean sediment traps. Deep-Sea Res., 37, 1285-1296. 
Mittelstaedt, E. 1987. Cyclonic cold-core eddy in the eastern North Atlantic. I. Physical description. Mar. Ecol. Prog. Ser., 39, 145-152.

Neuer, S., V. Ratmeyer, R. Davenport, G. Fischer and G. Wefer. 1997. Deep water particle flux in the Canary Islands region: seasonal trends in relation to long term satellite derived pigment data and lateral sources. Deep-Sea Res., I, 44, 1451-1466.

Newton, P. P., R. S. Lampitt, T. D. Jickells, P. King and C. Boutle. 1994. Temporal and spatial variability of biogenic particle fluxes during the JGOFS northeast Atlantic process studies at $47 \mathrm{~N}$, 20W. Deep-Sea Res. I, 41, 1617-1642.

Oschlies, A. and V. Garçon. 1998. Eddy-induced enhancement of primary production in a model of the North Atlantic Ocean. Nature, 394, 266-269.

Paffenhoffer, G. A. and S. C. Knowles. 1979. Ecological implications of fecal pellet size, production and consumption by copepods. J. Mar. Res., 37, 35-49.

Passow, U. 1990. Species specific sedimentation and sinking velocities of diatoms, in Sediment Trap Studies in the Nordic Countries, Symposium Proceedings, Kristineberg Marine Biological Station, Sweden, 21-25 November 1990, 176-189.

Peinert, R. and J. C. Miguel. 1994. The significance of frontal processes for vertical particle fluxes: A case study in the Alboran Sea (SW Mediterranean Sea). Mar. Syst., 5, 377-389.

Pfannkuche, O. 1993. Benthic response to the sedimentation of particulate organic matter at the BIOTRANS station, 47N, 20W. Deep-Sea Res., II, 40, 135-151.

Pollard, R. T. and L. A. Regier. 1992. Vorticity and vertical circulation at an ocean front. J. Phys. Oceanogr., 22, 609-625.

Robinson, A. R., D. J. McGillicuddy, J. Calman, H. W. Ducklow, M. J. R. Fasham, F. E. Hoge, W. G. Leslie, J. J. McCarthy, S. Podewski, D. L. Porter, G. Saure and J. A. Yoder. 1993. Mesoscale and upper ocean variabilities during the 1989 JGOFS bloom study. Deep-Sea Res., II, 40, 9-36.

Roden, G. J. 1972. Large scale upwelling of northwestern Mexico. J. Phys. Oceanogr., 2, 184-189.

Rossby, T., J. Price and D. Webb. 1986. The spatial and temporal evolution of a cluster of SOFAR floats in POLYMODE Local Dynamics Experiment. J. Phys. Oceanogr., 16, 428-442.

Savidge, G., D. R. Turner, P. H. Burkhill, A. J. Watson, M. V. Angel, R. D. Pingree, H. Leach and K. J. Richards. 1992. The BOFS 1990 Spring Bloom Experiment: Temporal evolution and spatial variability of the hydrographic field. Progr. Oceanogr., 29, 235-281.

Siegel, D. A. and W. G. Deuser. 1997. Trajectories of sinking particles in the Sargasso Sea: Modelling of statistical funnel above deep-ocean sediment traps. Deep-Sea Res., 44, 1519-1541.

Siegel, D. A., T. C. Granata, A. F. Michaels and T. D. Dickey. 1990. Mesoscale eddy diffusion, particle sinking and interpretation of sediment trap data. J. Geophys. Res., 95, 5305-5311.

Small, L. F., S. W. Fowler and M. Y. Unlu. 1979. Sinking rates of natural copepod fecal pellets. Mar. Biol., 51, 233-241.

Smayda, T. J. 1970. The suspension and sinking of phytoplankton in the sea. Oceanogr. Mar. Biol. Ann. Rev., 8, 353-414.

Smetacek, V. S. 1985. Role of sinking diatom life-history cycles: Ecological, evolutionary and geological significance. Mar. Biol., 84, 239-251.

Sverdrup, H. U. 1953. On conditions for the vernal blooming of phytoplankton.J. Cons. Int. Explor. Mer., 18, 287-295.

Takahashi, K. and A. W. H. Bè. 1984. Planktonic foraminifera: factors controlling sinking speed. Deep-Sea Res., 31, 1477-1500.

Taylor, A. H. and J. A. Stephens. 1993. Diurnal variations of convective mixing and the spring bloom of phytoplankton. Deep-Sea Res., 40, 389-408. 
Townsend, D. W., L. M. Cammen, M. P. Holligan, D. E. Campbell and N. R. Pettigrew. 1994. Causes and consequences of variability in the timing of spring phytoplankton blooms. Deep-Sea Res., 41, 747-765.

Urrere, M. A. and G. A. Knauer. 1981. Zooplankton fecal pellet fluxes and vertical transport of particulate organic material in the pelagic environment. J. Plankton Res., 3, 369-387.

Vinogradov, M. Ye. 1961. Food sources of the deep-water fauna. Speed and decomposition of dead pteropoda. Doklady Akademiya Nauk SSSR, Oceanology (english translation), 136-141, $39-42$.

Waniek, J. and B. Zeitzschel. 2001. Eddy field characteristics at the JGOFS quasi-time series station in the northeast Atlantic, the Biotrans site (47N, 20W). J. Mar. Res. (submitted).

Wefer, G. and G. Fischer. 1993. Seasonal patterns of vertical particle flux in equatorial and coastal upwelling areas of the eastern Atlantic. Deep-Sea Res. I, 40, 1613-1645.

Williams, R. G. and M. J. Follows. 1998. The Ekman transfer of nutrients and maintenance of new production over the North Atlantic. Deep-Sea Res. I, 45, 461-489.

Yoder, J. A., J. Aiken, R. N. Swift, F. E. Hoge and P. M. Stegmann. 1993. Spatial variability in near surface chlorophyll $a$ fluorescence measured by the Airborne Oceanographic Lidar (AOL). Deep-Sea Res., II, 40, 37-54.

Zeitzschel, B., P. Diekmann and L. Uhlman. 1978. A new multiple sediment trap. Mar. Biol., 45, 285-288. 